\title{
25 Research Square

\section{Health care seeking behavior for common childhood morbidities in Ethiopia: The effects of maternal behavior and access to key health services}

Nigatu R Geda ( $\sim$ negyon@yahoo.com )

Addis Ababa University

\section{Cindy Xin Feng}

University of Saskatchewan

\section{Susan J Whiting}

University of Saskatcjewan

\section{Rein Lepnurm}

University of Saskatchewan Western College of Veterinary Medicine

\section{Carol J Henry}

University of Saskatchewan

\section{Bonnie Janzen}

University of Saskatchewan

\section{Research}

Keywords: Acute Respiratory IIIness, Diarrhea, Determinants, Health Services, Morbidity, Ethiopia.

Posted Date: July 27th, 2020

DOI: https://doi.org/10.21203/rs.3.rs-44306/v2

License: (c) This work is licensed under a Creative Commons Attribution 4.0 International License.

Read Full License 
The authors have withdrawn this preprint from Research Square 